\title{
The response of human bone marrow to chronic cigarette smoking
}

\author{
S.F. van Eeden, J.C. Hogg
}

\begin{abstract}
The response of human bone marrow to chronic cigarette smoking. S.F. van Eeden, J.C. Hogg. (C) ERS Journals Ltd 2000.

ABSTRACT: Chronic cigarette smoking in humans causes leukocytosis. Animal studies show that chronic smoking shortens the transit time of polymorphonuclear leukocytes (PMNLs) through the bone marrow. The present study examines the response of human bone marrow to chronic cigarette smoking.

Three characteristics of peripheral blood PMNLs that indicate active bone marrow release (band cell counts, surface L-selectin expression and myeloperoxidase (MPO) content), were measured in 38 healthy chronic smokers $(23 \pm 5$ pack-yrs) and 15 ageand sex-matched nonsmoking controls.

The total white cell $\left(6.8 \pm 0.3 \times 10^{9}\right.$ versus $5.3 \pm 0.2 \times 10^{9}$ cells $\left.\cdot \mathrm{L}^{-1}, \mathrm{p}<0.0001\right)$ and PMNL (4.2 $\pm 0.18 \times 10^{9}$ versus $3.2 \pm 0.1 \times 10^{9}$ cells $\left.\cdot \mathrm{L}^{-1}, \mathrm{p}<0.003\right)$ counts were higher in smokers as were the percentage $(4.8 \pm 0.6$ versus $1.1 \pm 0.2, p<0.0001)$ and total number $\left(0.21 \pm 0.04 \times 10^{9}\right.$ versus $0.03 \pm 0.001 \times 10^{9}$ cells $\left.\cdot \mathrm{L}^{-1}, \mathrm{p}<0.01\right)$ of band cells. Flow cytometry showed that the mean fluorescence intensity (MFI) of L-selectin $(3.2 \pm 0.2$ versus $2.6 \pm 0.1, p<0.05)$ on PMNLs was higher in smokers. There was no difference in the baseline or $N$-formyl-methionyl-leucyl-phenylalanine-stimulated expression of CD63 or CD18/CD11b (surface markers of PMNL activation) between smokers and controls. The MPO content of PMNLs was higher in smokers $(3.4 \pm 0.3$ versus $1.7 \pm 0.2 \mathrm{MFI}$, p $<0.05)$. Smokers with a low $(<75 \%$ of the predicted value) diffusing capacity of the lung for carbon monoxide had higher PMNL MPO levels than smokers with a diffusing capacity of $>75 \%$ pred $(p<0.05)$.

In conclusion, chronic smoking causes phenotypic changes in circulating polymorphonuclear leukocytes that are characteristic of chronic stimulation of the bone marrow and it is speculated that the increased number of immature polymorphonuclear leukocytes contributes to the chronic lung inflammation associated with cigarette smoking.
\end{abstract}

Eur Respir J 2000; 15: 915-921.

Pulmonary Research Laboratory, University of British Columbia, St Paul's Hospital, Vancouver, British Columbia, Canada.

Correspondence: S.F. van Eeden, UBC Pulmonary Research Laboratory, St Paul's Hospital, 1081 Burrard Street, Vancouver, British Columbia V6Z 1Y6, Canada. Fax: 16048068351

Keywords: Band cells cell adhesion molecules

L-selectin

myeloperoxidase

neutrophils

polymorphonuclear leukocytes

Received: September 281999

Accepted after revision February 52000

Supported by Grant No. 4219 from the Medical Research Council of Canada, and partially funded by RJ Reynolds, Inc.

Chronic cigarette smoking produces a $20-25 \%$ increase in the peripheral blood leukocyte count compared with nonsmoking control subjects $[1,2]$. This chronic increase in circulating leukocyte number correlates with a decrease in lung function over time [3, 4], and polymorphonuclear leukocytes (PMNLs) have been implicated in the pathogenesis of both chronic airways obstruction and emphysema associated with cigarette smoking [5]. The destruction of alveolar walls, the hallmark of emphysema, has been postulated to result from a functional proteolytic imbalance created by cigarette smoking [5]. This imbalance may be augmented by the sequestration of PMNLs in lung capillaries during smoking and the ability of the oxidative potential of PMNLs to inactivate the major antiprotease for neutrophil elastase, $\left(\alpha_{1}\right.$-antitrypsin [610].

The number of circulating PMNLs is influenced by their rate of production in the bone marrow, their release into the circulation, the exchange between the circulating and the marginated pool of intravascular PMNLs and their permanent removal from the circulation. PMNLs are produced in the bone marrow, which is the site of proliferation, terminal differentiation and maturation [11]. In previously reported animal studies, it was found that cigarette smoke exposure accelerated the release of PMNLs from the bone marrow, which was postulated to be mediated by soluble factors released from the lung [12]. Alveolar macrophages are an important source of pro-inflammatory mediators and, when stimulated by cigarette smoke, produce factors such as tumour necrosis factor- $\alpha$ (TNF- $\alpha$ ), interleukin (IL)-1, IL-6, IL-8 and haematopoietic growth factors such as granulocyte-macrophage colony-stimulating factor (GM-CSF) and granulocyte colony-stimulating factor (G-CSF) $[13,14]$. When these factors circulate they are capable of stimulating haematopoietic precursors resulting in accelerated proliferation and release of PMNLs from the bone marrow into the circulation $[15,16]$.

The hallmark of an accelerated release of PMNLs from the bone marrow is the presence of an increase in the number of circulating nonsegmented PMNLs or band cells $[17,18]$. The L-selectin level on PMNLs also serves as a marker of younger cells in the circulation $[19,20]$, and this molecule could contribute to PMNL sequestration in lung capillaries. Myeloperoxidase (MPO), an enzyme of 
the primary granules of PMNLs, is produced at an early stage of PMNL proliferation in the bone marrow and is divided between progeny with subsequent cell divisions [11]. The authors postulate that an accelerated transit of PMNLs through the mitotic pool of the marrow could cause PMNLs to skip divisions resulting in the release of cells into the circulation with a higher MPO content $[11$, 12].

The present study compares the phenotypic characteristics of circulating PMNLs in smokers and nonsmokers to test the hypothesis that cigarette smoking in humans is associated with bone marrow stimulation and an accelerated release of PMNLs into the circulation.

\section{Methods}

\section{Subjects}

The study population consisted of 38 healthy adult smokers and 15 age- and sex-matched nonsmoking controls. The study was approved by the Human Experimentation Committee of St Paul's Hospital and the University of British Columbia.

Inclusion criteria for smokers were: age $25-50 \mathrm{yrs}$; a smoking history of $\geq 15$ cigarettes $\cdot$ day $^{-1}$ for $>3$ yrs; and healthy with no symptoms or clinical signs of lung or other inflammatory disease and on no medication. Similarly, the controls were aged 25-50 yrs, lifetime nonsmokers and healthy with no underlying inflammatory disease. On enrolment, all subjects completed a health questionnaire and underwent physical examination, chest radiography, electrocardiography and lung function tests. These tests were done to exclude subjects with acute or chronic diseases that could influence circulating leukocyte counts.

Lung function tests were performed in the following manner: forced vital capacity and forced expiratory volume in one second (FEV1) were determined using spirometry; residual volume was determined with the helium-dilution method; total lung capacity was assessed with plethysmography; and diffusing capacity of the lung for carbon monoxide ( $D \mathrm{~L}, \mathrm{CO})$ was obtained using a single-breath method and values corrected for alveolar volume and haemoglobin concentration. The predicted values for each subject based on sex, age and height were obtained from standard tables. Data are expressed as a percentage of the predicted value.

Smokers were requested not to change their smoking habits prior to venepuncture and blood was collected from all subjects between 8:00 and 10:00 h. The smoking status of subjects was assessed from carboxyhaemoglobin concentrations (IL-482 CO-Oximeter; System Instrumentation, Lexington, MA, USA).

\section{Leukocyte counts}

Blood samples were collected in standard tubes containing potassium ethylene diamine tetra-acetic acid (EDTA), (Vacutainer; Becton Dickinson, Rutherford, NJ, USA). White blood cell counts were performed using a Sysmex model E4000 (Sysmex Tao, Japan) and differential counts were made on Wright-stained blood smears by counting 100 leukocytes in randomly selected fields of view. Band cells were identified using the American Pathology Society criteria [21] and the percentage of band cells obtained by counting 100 PMNLs in randomly selected fields of view. Two independent observers who were naive to the identity of the slides performed these counts and interobserver variability was small.

\section{Flow cytometry}

Expression of L-selectin, CD11b and CD63 on polymorphonuclear leukocytes. The surface expression of Lselectin, CD11b and CD63 [21] on PMNLs was quantified by means of immunofluorescence using flow cytometry. A whole blood method was used to label PMNLs to prevent artefactual changes in sensitive surface molecules [22]. Whole blood $(100 \mu \mathrm{L})$ was incubated with $200 \mu \mathrm{L}$ phosphate-buffered saline (PBS), $\mathrm{pH} 7.3$ and $0.1 \mu \mathrm{g}$ fluorescein isothiocyanate (FITC)-conjugated antihuman Lselectin DREG 56 (Immunotech, Marseille, France), 0.1 $\mu \mathrm{g}$ phycoerythrin (PE)-conjugated antihuman CD11b (Dakopatts, Copenhagen, Denmark) or $0.1 \mu \mathrm{g}$ FITCconjugated antihuman CD63 (Immunotech, Marseille, France) for $10 \mathrm{~min}$ at room temperature $\left(20^{\circ} \mathrm{C}\right)$ in the dark. Nonimmune mouse FITC-conjugated immunoglobulin G2a (Sigma Chemical Co, St Louis, MO, USA) in the same concentration served as a negative control. Cells were washed with PBS, the red blood cells in the samples lysed (Immunolyse; Coulter Electronics, Hialeah, FL, USA), leukocytes fixed with $1 \%$ paraformaldehyde and stored at $4{ }^{\circ} \mathrm{C}$. Cells were analysed using flow cytometry (Epics XL; Coulter Electronics) within $24 \mathrm{~h}$. Analysis gates for PMNLs were established using distinctive forward- and side-scatter profiles and results expressed as the mean fluorescence intensity (MFI) of 5,000 cells.

To determine whether PMNLs are primed, $100 \mu \mathrm{L}$ of whole blood was incubated for $10 \mathrm{~min}$ in a waterbath at $37^{\circ} \mathrm{C}$ with $10 \mathrm{nM}$ cytochalasin $\mathrm{B}$ in $0.02 \%$ dimethyl sulphoxide (Sigma Chemical Co), the receptor stimulus $N$ formyl-methionyl-leucyl-phenylalanine (fMLP; $10 \mathrm{nM}$ final concentration; Sigma Chemical Co) was added and the blood was incubated for $10 \mathrm{~min}$. The reaction was terminated by washing the sample twice with a large volume of PBS (15 mL). Cells were labelled for L-selectin, CD11b and CD63 and analysed as described above. CD63 is a primary granule membrane protein and surface expression is a marker of degranulation of primary granules containing MPO [23].

\section{Leukocyte myeloperoxidase levels}

The MPO content of PMNLs was determined using the FITC-conjugated monoclonal antibody ((Dakopatts, Copenhagen, Denmark). Briefly, $100 \mu \mathrm{L}$ of whole blood and $100 \mu \mathrm{L}$ of fixative (reagent A of "Fix and Permß"; Caltag, Austria) were incubated for $10 \mathrm{~min}$ at room temperature, washed twice in PBS, and the cell pellet suspended in 100

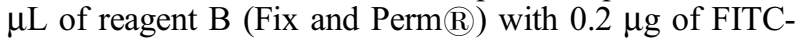
conjugated MPO. Cells were incubated for $15 \mathrm{~min}$, washed in PIBS, fixed with $1 \%$ paraformaldehyde and stored at $4{ }^{\circ} \mathrm{C}$. Cells were analysed using flow cytometry as described above.

\section{Double labelling}

To evaluate the relationship between PMNL MPO levels and surface markers, leukocytes were labelled for MPO 
(FITC) as well as either L-selectin or CD11b. Whole blood $(100 \mu \mathrm{L})$ was incubated with $200 \mu \mathrm{L}$ PBS, pH 7.3 and 0.1 $\mu \mathrm{g}$ PE-conjugated antihuman L-selectin (immunotech); or $0.1 \mu \mathrm{g}$ of PE-conjugated antihuman CD11b for $10 \mathrm{~min}$ at room temperature in the dark. Nonimmune mouse PEconjugated IgG2a (Sigma Chemical Co) in the same concentration served as negative control. Cells were prepared as described for MPO labelling. Cells were analysed using flow cytometry and either L-selectin or CD11b were analysed on FITC-positive (MPO label) PMNLs that had low (30\% of PMNLs with the lowest levels of MPO) and high (30\% of PMNLs with the highest levels of MPO) levels of MPO. A total of 5,000 cells were analysed in each population.

\section{Statistical analysis}

All values are expressed as mean \pm SEM. Analysis of variance was carried out to compare leukocyte counts, cell surface markers and PMNL myeloperoxidase content. Bonferroni corrections for multiple comparisons were performed where appropriate and a $p$-value of $<0.05$ was accepted as significant.

\section{Results}

\section{Subject characteristics}

Table 1 shows the demographic data, carboxyhaemoglobin levels and lung function of the two groups. The groups were comparable with regard to age and sex. Smokers smoked 15-40 cigarettes. day $^{-1}$ at the time of the study with a mean $23 \pm 1$ pack-yrs (range 15-41) history. This was reflected in higher carboxyhaemoglobin levels $(5 \pm 0.4 \%)$ than controls $(2.2 \pm 0.2 \%)$. Both FEV1 $(\mathrm{p}<0.05)$ and $D$ L,CO $(\mathrm{p}<0.001)(\%$ pred $)$ were lower in the smokers but values were still within the accepted normal range.

\section{Peripheral blood cell counts}

Table 2 summarizes the blood cell counts in the two groups. Peripheral white blood cell counts were higher in the smokers, mainly due to an increase in PMNL counts

Table 1. - Demographic parameters

\begin{tabular}{lccc}
\hline & Smokers & Controls & p-value \\
\hline Subjects n & 38 & 15 & \\
Age & $37 \pm 1.2$ & $34 \pm 2.9$ & NS \\
Sex ratio male/female & 0.48 & 0.58 & NS \\
Smoking & & & \\
Cigarettes-day ${ }^{-1 *}$ & $23 \pm 5$ & 0 & - \\
Pack-yrs** & $23 \pm 1$ & 0 & - \\
FEV \% pred & $105 \pm 2.5$ & $114 \pm 3.2$ & 0.05 \\
DL,CO \% pred & $83 \pm 2.6$ & $103 \pm 3.1$ & 0.001 \\
TLC \% pred & $94 \pm 5$ & $103 \pm 6$ & NS \\
HbCO (\%) & $5.1 \pm 0.4$ & $2.2 \pm 0.2$ & 0.01 \\
\hline
\end{tabular}

Data are presented as mean \pm SEM. *: in the preceding 3 months; $* *$ : 20 cigarettes $\cdot$ day $^{-1}$ for $1 \mathrm{yr}$. FEV 1 : forced expiratory volume in one second; $D$ L,CO: diffusing capacity of the lung for carbon monoxide (corrected for alveolar volume and haemoglobin concentration); TLC: total lung capacity; HbCO: carboxyhaemoglobin; \% pred: percentage of the predicted value (for age, sex and height).
Table 2. - Peripheral blood leukocyte counts in smokers and nonsmoking controls

\begin{tabular}{lccc}
\hline & Smokers & Controls & p-value \\
\hline Subjects n & 38 & 15 & \\
Total leucs $10^{9}$ cells $\cdot \mathrm{L}^{-1}$ & $6.8 \pm 0.3$ & $5.3 \pm 0.2$ & 0.001 \\
PMNLs $10^{9}$ cells $\mathrm{L}^{-1}$ & $4.2 \pm 0.18$ & $3.2 \pm 0.19$ & 0.003 \\
Band cells $10^{9}$ cells $\cdot \mathrm{L}^{-1}$ & $0.18 \pm 0.04$ & $0.031 \pm 0.006$ & 0.01 \\
\multicolumn{1}{c}{$\%$} & $4.8 \pm 0.6$ & $1 \pm 0.2$ & 0.0001 \\
MCs $10^{9}$ cells $\cdot \mathrm{L}^{-1}$ & $2.6 \pm 0.16$ & $2.1 \pm 0.18$ & NS \\
\hline
\end{tabular}

Data are presented as mean \pm SEM. leuc: leukocyte; PMNL: polymorphonuclear leukocyte; MCs: mononuclear cells (including lymphocytes and monocytes).

$(\mathrm{p}<0.003)$. The total number $(\mathrm{p}<0.01)$ as well as the percentage $(p<0.0001)$ of nonsegmented PMNLs or band forms was higher $(p<0.01)$ in the smokers. The numbers of other leukocytes (lymphocytes, monocytes and eosinophils) were not different between the groups.
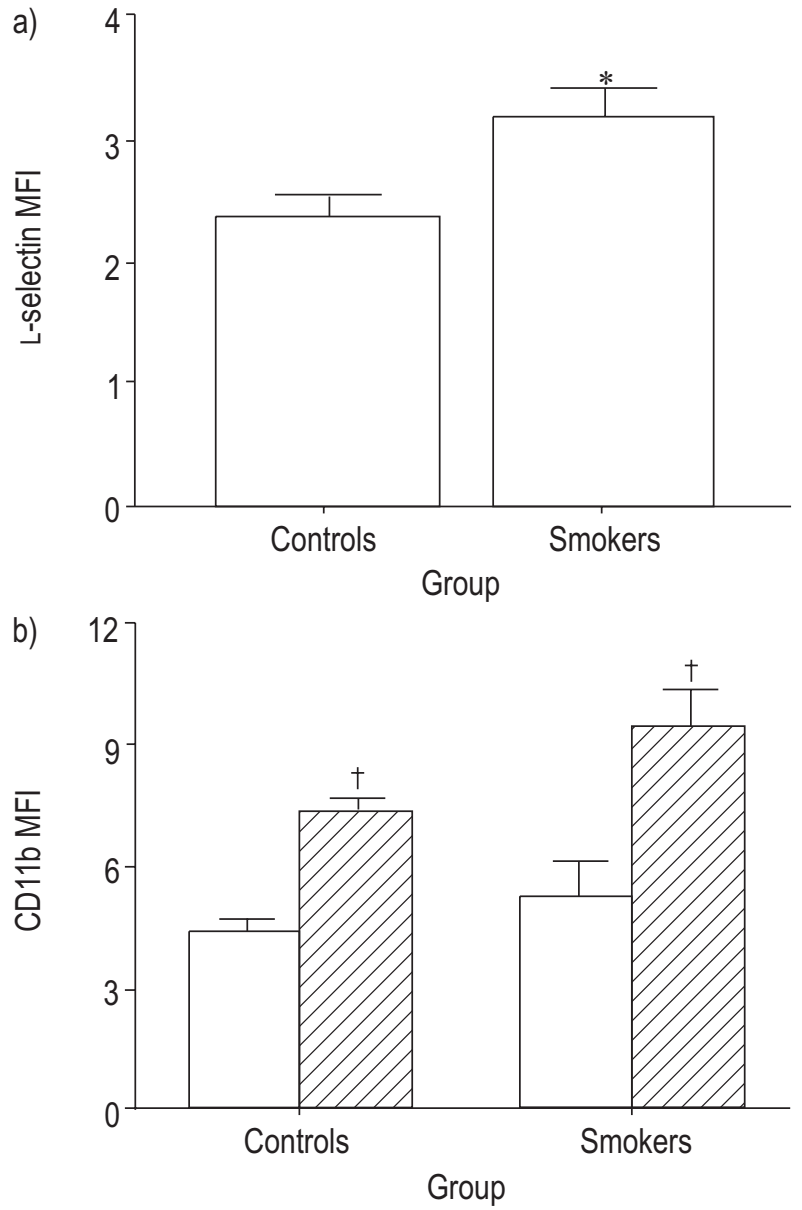

Fig. 1. - a) L-selectign expression on circulating polymorphonuclear leukocytes (PMNLs) as measured by flow cytometry using the monoclonal antibody DREG 56 (see Flow cytometry section). L-selectin levels on PMNLs in smokers were higher than in control subjects. b) CD11b expression on circulating PMNLs as measured by flow cytometry using a phycoerythin-conjugated monoclonal antibody (see Flow cytometry section). Baseline expression ( $\square$ ) between groups was similar. A similar increase in expression was observed following stimulation with $10 \mathrm{nM}$ $\mathrm{N}$-formyl-methionyl-leucyl-phenylalanine $(\mathscr{Z})$. Data are presented as mean \pm SEM (38 smokers and 15 controls). MFI: mean fluorescence intensity. ${ }^{*}: \mathrm{p}<0.05$ versus controls; ${ }^{+}: \mathrm{p}<0.05$ versus baseline. 
Surface L-selectin, CD11b and CD63 expression on circulating polymorphonuclear leukocytes

The expression of L-selectin on circulating PMNLs was higher in smokers (fig. 1a) and decreased to a similar extent in smokers and controls following fMLP stimulation (data not shown). There was no difference in the baseline CD11b levels between smokers and controls (fig. 1b) and stimulation of PMNLs with fMLP caused a more than two-fold increase in CD11b expression in smokers that was similar to changes in the controls (fig. 1b). Baseline CD63 expression was no different from background readings in both groups and increased to the same level with fMLP stimulation (1.8 \pm 0.2 in controls versus $1.84 \pm 0.1$ in smokers).

Myeloperoxidase levels in circulating polymorphonuclear leukocytes

Myeloperoxidase levels in PMNLs from smokers were higher than those from controls (fig. 2a). On subgroup
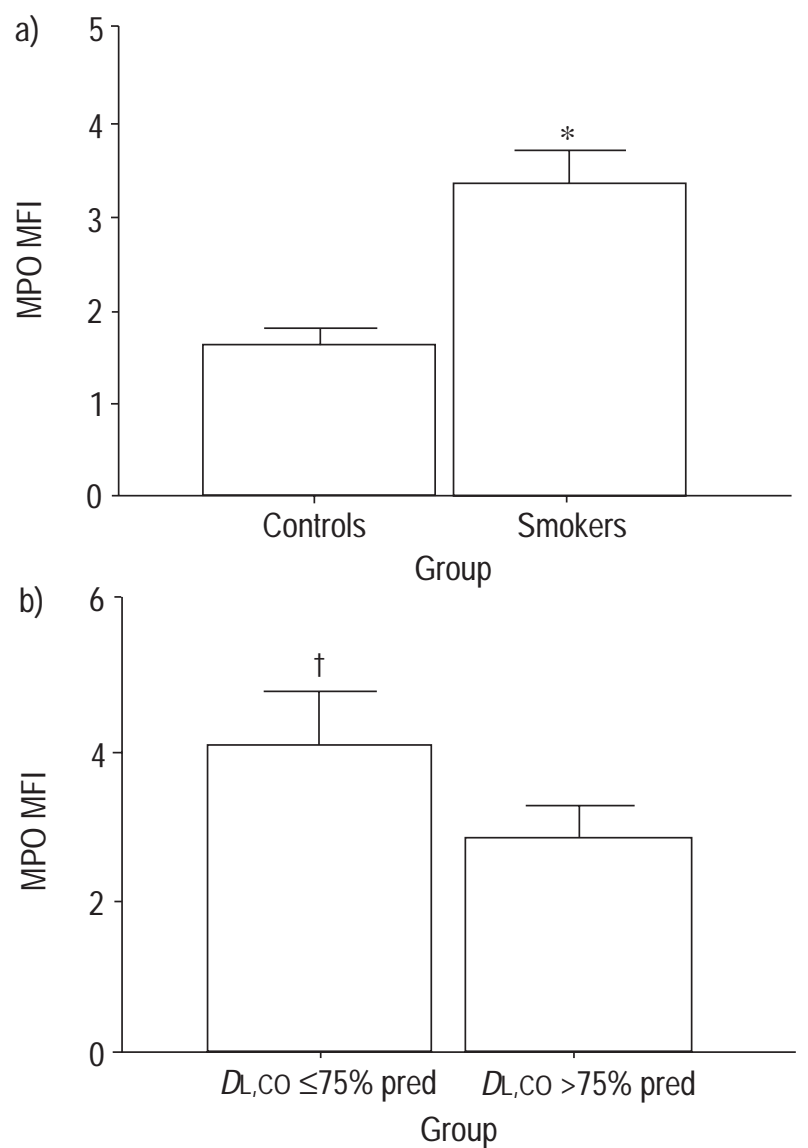

Fig. 2. - Myeloperoxidase (MPO) content of circulating polymorphonuclear leukocytes (PMNLs) as measured by flow cytometry using a fluorescein isothiocyanate-conjugated monoclonal antibody (see Double labelling section): a) in 38 smokers and 15 controls; and b) after dividing the subjects into those with a diffusing capacity of the lung for carbon monoxide ( $D \mathrm{~L}, \mathrm{CO})$ of $\geq 75 \%$ of the predicted value $(\mathrm{n}=21)$ and those with a $D L, C O$ of $>75 \%$ pred $(\mathrm{n}=17)$ (both corrected for alveolar volume and haemoglobin concentration). Data are presented as mean \pm SEM. MFI: mean fluorescence intensity. ${ }^{*}: \mathrm{p}<0.05$ versus controls; ${ }^{+}: \mathrm{p}<0.05$ versus $D$ L,CO $>75 \%$ pred.

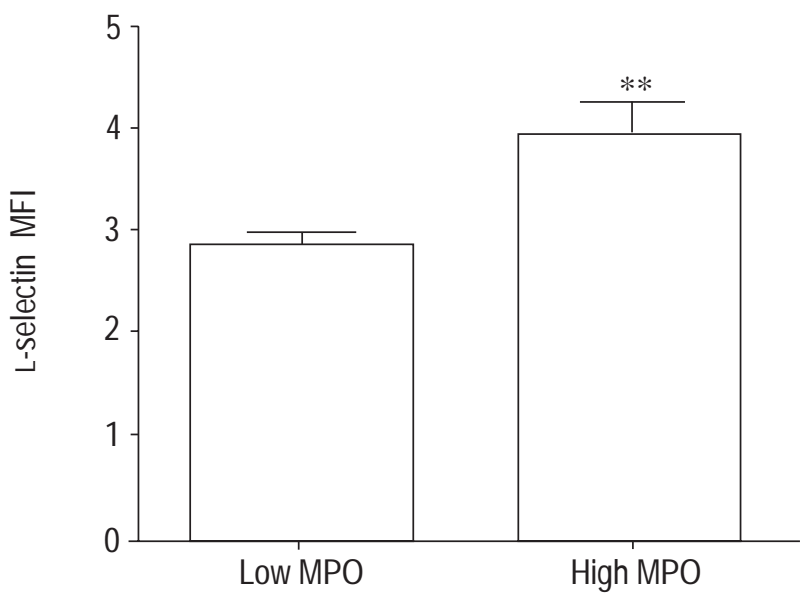

Fig. 3. - L-selectin expression on polymorphonuclear leukocytes (PMNLs) with high and low myeloperoxidase (MPO) levels. PMNLs were double labelled with fluorescein isothiocyanate-conjugated antiMPO monoclonal antibodies and phycoerythin-conjugated anti-Lselectin antibodies. L-selectin was measured on the $30 \%$ of PMNLs with the highest and lowest levels of MPO. Date are presented as mean \pm SEM. MFI: mean fluorescence intensity. $* *: p<0.01$ versus low MPO.

analysis, smokers were divided into those with a $D \mathrm{~L}, \mathrm{CO}$ of $\leq 75 \%$ pred $(\mathrm{n}=21)$ and those with a $D \mathrm{~L}, \mathrm{CO}$ of $>75 \%$ of pred $(n=17)$ (both corrected for alveolar volume). The current and past smoking history of these two groups was similar and there were no differences in their total white blood cell, PMNL and band cell counts (data not shown). However, the PMNL MPO content (fig. 2b) was significantly higher in the smokers with $D \mathrm{~L}$,CO of $<75 \%$ pred $(\mathrm{p}<0.05)$.

Double labelling experiments showed that PMNLs with high levels of MPO also have high levels of surface Lselectin (fig. 3). CD11b expression was similar in the PMNLs with high and low levels of MPO (data not shown).

\section{Discussion}

This study confirms previous findings that chronic cigarette smoke exposure caused leukocytosis and a neutrophilia [1-4]. In addition, the neutrophilia was associated with an increase in numbers of circulating band cells, a hallmark of early bone marrow release of PMNLs and an increase in L-selectin expression on PMNLs, indicating a larger number of PMNLs recently released from the bone marrow $[11,16]$. These two findings support the hypothesis that cigarette smoking stimulates the bone marrow. Based on previous animal studies $[12,24]$, it is suspected that this stimulation causes an accelerated transit time of PMNLs through the bone marrow, resulting in the release of younger less mature PMNLs into the circulation. These PMNLs that sequester preferentially in lung microvessels have a higher level of MPO (fig. 2a) [24] and could play an important role in the pathogenesis of smoke-induced lung disease.

Chronic smokers show a $20-30 \%$ increase in their circulating total white blood cell counts, primarily due to an increase in granulocytes, suggesting stimulation of the bone marrow with a higher turnover of these leukocytes 
[1-4]. An increase in circulating PMNL counts is a hallmark of the systemic response to stress $[17,18,25]$. Mild stress such as exercise increases the circulating PMNL counts without an increase in band cell counts [26], in contrast to more severe stress, such as infection, which causes an increase in circulating PMNL and band cell counts $[17,18]$. The neutrophilia in the smokers reported here was associated with a four-fold increase in the percentage of circulating band cells (table 2), which provides definitive evidence of accelerated bone marrow release of granulocytes.

The expression of the cell adhesion molecule, L-selectin, on circulating PMNLs was higher in the smokers compared to the control subjects. L-selectin is constitutively expressed on circulating PMNLs [27] and it has been shown that PMNLs released from the bone marrow as a result of stimuli such as intravascular complement activation [19] or pneumococcal pneumonia [20] express high levels of L-selectin. Studies from the authors' own $[28,29]$ and other [30] laboratories have shown that PMNLs in the maturation pool of the bone marrow express high levels of L-selectin and that active bone marrow release enriches the circulating pool with PMNLs expressing high levels of L-selectin [19, 20]. The present study shows that the circulating PMNLs of chronic smokers express higher levels of L-selectin than controls (fig. 1), suggesting that active bone marrow release of PMNLs into the circulation is an important mechanism for the granulocytosis induced by cigarette smoking.

MPO, present in the primary granules of PMNLs, is formed at an early stage (promyelocyte) in the bone marrow and the number of these granules per cell is reduced by mitoses as the cells divide in the mitotic pool [11]. BRIDGES et al. [31] reported that PMNLs from smokers have greater MPO activity than those from nonsmokers, whereas other workers found no difference [32]. The present study supports the findings of BRIDGES et al. [31] and DASH et al. [33] showing high MPO levels in the PMNLs of chronic smokers. The authors' previous animal studies show that chronic cigarette smoking shortens the transit time of myeloid cells through the mitotic pool in the marrow, and the authors suspect that PMNLs skip divisions in the marrow and are released into the circulation with high MPO levels [12]. The double labelling experiments also showed that the PMNLs with the highest levels of MPO have the highest levels of surface L-selectin (fig. 3). This finding suggests that smoking causes the release of a population of younger cells with high MPO levels due to a rapid transit through the bone marrow [28, 34].

The increase in circulating band cell counts, the high levels of L-selectin on circulating PMNLs and the increased MPO content of circulating PMNLs in smokers all support the hypothesis that cigarette smoking causes bone marrow stimulation. There is a growing body of evidence that PMNLs released from activated bone marrow are more harmful to the host [20, 24, 28, 35, 36]. L-selectin initiates the adherence of PMNLs to endothelium under conditions of flow and has been shown to be important for the recruitment of PMNLs to inflamed tissue [37, 38]. Doyle et al. [39] have shown that L-selectin contributes to the prolonged sequestration of PMNLs in lung capillaries. The high levels of L-selectin on PMNLs (fig. 1) may contribute to prolonged retention of PMNLs in lung capillaries and also signifies younger cells that are less de- formable, which could further enhance the retention of these cells in lung capillaries. The finding of high levels of L-selectin on PMNLs from smokers is in contrast to that of PiTzER et al. [40] of no changes in levels of CD18 and L-selectin on circulating PMNLs from smokers. They postulate that PMNLs with enhanced adhesion properties due to activation by cigarette smoke are all sequestered in lung microvessels.

There is a marked increase in the mobility, deformability and chemotactic responsiveness of PMNLs during their maturation in the postmitotic pool in the bone marrow [4143]. PMNLs in the marrow are larger and less deformable than those in peripheral blood [41], and when prematurely released are predisposed to sequestration in lung capillaries [20, 28]. MACNEE et al. [44] have shown that PMNLs are retained in the human lung by cigarette smoking, and recent studies by TERASHIMA et al. [24] have shown that immature PMNLs are preferentially sequestered in lung microvessels. Assuming a cardiac output of $5 \mathrm{~L} \cdot \mathrm{min}^{-1}$ and using circulating band cells as representative of younger immature PMNLs, the calculated burden of these immature PMNLs in the lung is $\sim 5.8$ times higher in smokers than in controls $\left(1.296 \times 10^{9}\right.$ versus $2.23 \times$ $10^{11}$ band cells $24 \mathrm{~h}^{-1}$ ). Activation of these PMNLs sequestered in the pulmonary capillaries could contribute to the destruction of alveolar walls and the development of emphysema.

Activated PMNLs release an array of toxic products that include proteolytic enzymes, reactive oxygen species and cationic proteins that have been implicated in the damage to alveolar walls leading to emphysema [5-10]. The increased levels of MPO in the PMNLs of smokers (fig. 2a) would show increased redox potential when activated by cigarette smoke. Similar to MPO, other proteolytic enzymes such as elastase, cathepsin $G$ and proteinase 3 are also present in the primary granules and preformed early in cell division in the marrow. The authors postulate that PMNLs loaded with these enzymes are retained in lung capillaries and, when activated by cigarette smoking, could release these enzymes (including MPO) that are damaging to alveolar walls. As only $15-20 \%$ of smokers develop emphysema [45], for reasons that are not clear, it is possible that the bone marrow response to cigarette smoking is an important determinant for the development of emphysema. The higher MPO levels in healthy smokers with a low $D$ L,CO (fig. 2b) support the hypothesis that the response of the bone marrow to cigarette smoking could be an important determinant for the development of lung destruction and emphysema.

The mechanisms that control the release of PMNLs from the bone marrow into the circulation are poorly understood. Releasing factors such as glucocorticoids, endotoxins, complement fragments and haematopoietic growth factors such as GM-CSF and G-CSF have all been implicated in the initiation of PMNL release [46, 47]. Stimulation of the bone marrow by cigarette smoke is probably mediated by soluble factors released from the lung. Alveolar macrophages are an important source of pro-inflammatory soluble factors and when stimulated by cigarette smoke produce factors such as TNF- $\alpha$, IL-1, IL8 and GM-CSF $[13,14]$. These factors are capable of stimulating haematopoietic precursors in the marrow and cause the release of granulocytes from the bone marrow into the circulation $[46,47]$. 
In conclusion circulating polymorphonuclear leukocytes from smokers have phenotypic characteristics that indicate that they are released from a stimulated bone marrow. These phenotypic characteristics contribute to the preferential sequestration of polymorphonuclear leukocytes in the lung (cell immaturity and high L-selectin expression), and could enhance their ability to damage alveolar walls (high myeloperoxidase content). The authors postulate that the response of bone marrow to cigarette smoking plays an important role in the pathogenesis of chronic obstructive lung disease.

Acknowledgements. The authors wish to thank J. Hards and D. Zamfir for technical assistance and Y. D'yachkova for statistical analysis.

\section{References}

1. Corre F, Lellouch J, Schwartz D. Smoking and leukocyte counts: results of an epidemiological survey. Lancet 1971; ii: $632-634$.

2. Taylor RG. Smoking and the leukocyte count. Eur J Respir Dis 1987; 71: 65-68.

3. Chan Yeung M, Buncio AD. Leukocyte count, smoking and lung function. Am J Med 1984; 76: 31-37.

4. Weiss ST, Segal MR, Sparrow D, Wager C. Relation of FEV1 and peripheral blood leukocyte count to total mortality: the normative aging population. Am J Epidemiol 1995; 142: 493-498.

5. Janoff A. Biochemical links between cigarette smoking pulmonary emphysema. J Appl Physiol 1983; 55: 285293.

6. Hunninghake GW, Crystal RG. Cigarette smoking and lung destruction: accumulation of neutrophils in the lungs of cigarette smokers. Am Rev Respir Dis 1983; 128: 833838.

7. Ludwig PW, Hoidal JR. Alternations in leukocyte oxidative metabolism in cigarette smokers. Am Rev Respir Dis 1982; 126: 977-980.

8. Blue M, Janoff A. Possible mechanisms of emphysema in cigarette smokers. Am Rev Respir Dis 1987; 117: $317-$ 325.

9. Carrell RW. Alpha1-antitrypsin: molecular pathology, leukocytes, and tissue damage. J Clin Invest 1986; 78 : $1427-1431$.

10. Janoff A, Raju L, Dearing R. Levels of elastase activity in bronchoalveolar lavage fluids in healthy smokers and nonsmokers. Am Rev Respir Dis 1983; 127: 540-544.

11. Bainton DF. Phagocytic cells: Developmental biology of neutrophils and eosinophils. In: Gallin JI, Goldstein IM, Snyderman R, eds. Inflammation: Basic Principles and Clinical Correlations. New York, Raven Press, 1992; pp. 265-280.

12. Terashima TT, Wiggs B, English D, Hogg JC, van Eeden SF. Effect of smoking on the bone marrow. Am J Respir Crit Care Med 1997; 155: 1021-1026.

13. Francus T, Romano PM, Manzo G, Fonacier IL, Arango CN, Szabo P. IL-1, IL-6, and PDGF mRNA expression in alveolar cells following stimulation with a tobacco derived antigen. Cell Immunol 1992; 145: 156-174.

14. de Godoy I, Donahoe M, Calhoun WJ, Mancino J, Rogers RM. Elevated TNF- $\alpha$ production by peripheral blood monocytes of weight losing COPD patients. Am J Respir Crit Care Med 1996; 153: 633-637.
15. Platzer E. Human hematopoietic growth factors. Eur $J$ Hematol 1989; 42; 1-15.

16. Cronkite EP. Analytical review of structure and regulation of hemopoiesis. Blood Cells 1988; 14; 313-328.

17. Boggs DR. The kinetics of neutrophilic leukocytes in health and disease. Semin Hematol 1967; 4: 359-386.

18. Malech HL, Gallin JI. Neutrophils in human diseases. $N$ Engl J Med 1987; 317: 687-694.

19. Van Eeden S, Miyagashima R, Haley L, Hogg JC. Lselectin expression increases on peripheral blood polymorphonuclear leukocytes during active marrow release. Am J Respir Crit Care Med 1995; 151: 500-507.

20. Lawrence E, van Eeden SF, English D, Hogg JC. Polymorphonuclear leukocyte (PMN) in streptococcal pneumonia: evidence of impaired migration of PMN recently released from the marrow. Am J Respir Cell Mol Biol 1996; 14: 217-224.

21. College of American Pathologists. Quality Evaluation Program: 1971 Survey Manual. Chicago, College of American Pathologists, 1971; pp. 11-17.

22. Youssef PP, Mantzioris BX Roberts-Thomson PJ, Ahern MJ, Smith MD. Effects of ex vivo manipulation on the expression of cell adhesion molecules on neutrophils. $J$ Immunol Methods 1995; 186: 217-224.

23. Skubitz KM, Campbell KD, Iida J, Skubitz APN. CD63 associated tyrosine kinase activity and CD18/CD11 transmits an activating signal in neutrophils. J Immunol 1996; 157: 3617-3626.

24. Terashima T, Klut ME, English D, Hards J, Hogg JC, van Eeden SF. Chronic cigarette smoking causes sequestration of polymorphonuclear leukocytes released from the bone marrow in pulmonary capillaries. Am J Respir Cell Mol Biol 1998; 20: 171-177.

25. Hubl W, Andert S, Thum G, Ortner S, Bayer PM. Value of neutrophil CD16 expression for the detection of left shift and acute phase response. Am J Pathol 1997; 107: 187196.

26. Foster NK, Martin JB, Rangno RE, Hogg JC. Leukocytosis of exercise; role of cardiac output and catecholamines. J Appl Physiol 1986; 61: 2218-2221.

27. Jutila MA, Rott L, Berg EL, Butcher EC. Function and regulation of the neutrophil MEL-14 antigen in vivo: comparison with LFA-1 and Mac-1. J Immunol 1989; 143: 3318-3324.

28. van Eeden SF, Kitagawa Y, Klut ME, Lawrence E, Hogg JC. Polymorphonuclear leukoctes released from the bone marrow preferentially sequester in lung microvessels. Microcirculation 1997; 4: 369-380.

29. Nakagawa M, Bondy GIP, Waisman MD, Minshall D, Hogg JC, Van Eeden SF. The effect of glucocorticoids on the expression of L-selectin on polymorphonuclear leukocytes. Blood 1999; 93: 2730-2737.

30. Lund-Johansen F, Terstappen LW. Differential surface expression of cell adhesion molecules during granulocyte maturation. J Leukoc Biol 1993; 54: 47-55.

31. Bridges RB, Fu MC, Rehm SR. Increased neutrophil myeloperoxidase activity associated with cigarette smoking. Eur J Respir Dis 1985; 67: 84-93.

32. Corberand J, Nguyen F, Do AH, et al. Effects of tobacco smoke on the functions of polymorphonuclear leukocytes. Infect Immun 1979; 23: 577-581.

33. Dash S, Sen S, Behera D. High neutrophil myeloperoxidase activity in smokers. Blood 1991; 77: 1619.

34. Terashima T, Wiggs B, English D, Hogg JC, van Eeden SF. Polymorphonuclear leukocyte transit times in bone marrow during streptococcal pneumonia. Am J Physiol 1996; 271: L587-L592. 
35. Sato Y, van Eeden SF, English D, Hogg JC. Bacteremic pneumonia: bone marrow release and pulmonary sequestration of polymorphonuclear leukocytes. Crit Care Med 1998; 26: 501-509.

36. Sato Y, van Eeden SF, English D, Hogg JC. Bone marrow release and pulmonary sequestration of neutrophils during bacteremic subcutanuous infection. Am J Physiol 1998; 275; L255-L261.

37. Tedder TF, Steeber DA, Chen A, Engel P. The selectins: vascular adhesion molecules. FASEB J 1995; 9: 866873.

38. Kansas GS. Selectins and their ligands. Blood 1996; 88: 3259-3287.

39. Doyle NA, Bhagwan SD, Meek BB, et al. Neutrophil margination, sequestration, and emigration in the lungs of L-selectin-deficient mice. J Clin Invest 1997; 99: 526533.

40. Pitzer JE, Del Zoppo GJ, Schmidt-Schönbein GW. Neutrophil activation in smokers. Biorheology 1996; 33: 4558.

41. Litchman MA, Weed RI. Alternation of cell periphery during granulocyte maturation: relationship to cell function. Blood 1972; 39; 301-306.

42. Giordano GF, Licthman MA. Marrow egress: the central interaction between barrier pore size and cell maturation. J Clin Invest 1973; 52: 616-621.

43. Maloney MAT, Patt HM. Granulocyte transit from bone marrow to blood. Blood 1968; 31: 195-201.

44. MacNee W, Wiggs B, Belzberg AS, Hogg JC. The effect of cigarette smoking on neutrophil kinetics in human lungs. $N$ Engl J Med 1989; 321: 924-928.

45. Lebowitz MD, Knudson RJ, Burrows B. Tucson epidemiological study of obstructive lung disease; methodology and prevalence of disease. Am J Epidemiol 1977; 102: 137-152.

46. Jagels MA, Hugli TE. Neutrophil chemotactic factors promote leukocytosis: a common mechanism for cellular recruitment from bone marrow. J Immunol 1992; 148: 1119-1128.

47. Lieschke GJ, Burgess AW. Granulocyte colony-stimulating factor and granulocyte-macrophage colony stimulating factor. $N$ Engl J Med 1992; 327: 28-35. 